\title{
SOCIOLOGIA CULTURAL APLICADA: Democracia e sociedade civil na América Latina
}

\author{
APPLIED CULTURAL SOCIOLOGY: \\ Democracy and civil society in Latin America
}

Rogério de Souza Medeiros*

ALEXANDER, Jeffrey; TOGNATO, Carlo. (Orgs.). The Civil Sphere in Latin America. Cambridge, UK: Cambridge University Press, 2018.

Antes de publicar The Civil Sphere in Latin America (2018), junto com Carlo Tognato, Jeffrey Alexander havia publicado em 2006 The Civil Sphere, um ambicioso livro de quase oitocentas páginas, que pretendia nada menos do que oferecer um modelo teórico abrangente o suficiente para lidar com os principais problemas encontrados nas sociedades democráticas contemporâneas, ao mesmo tempo em que almejava apresentar um arcabouço conceitual para a análise sociológica da sociedade civil. Enquanto contribuição teórica, aquele livro fazia parte dos esforços do autor, em conjunto com seu colega e colaborador Philip Smith (ALEXANDER; SMITH, 1993), em pavimentar o caminho para desenvolver um novo programa de pesquisa para a Sociologia Cultural. Para tanto, o livro oferecia um debate de fôlego acerca de autores centrais do pensamento social contemporâneo, de Marx a Tocqueville, de Gramsci a Habermas, passando por John Rawls, T.H. Marshall e Michel Foucault, na tentativa de estabelecer alguns argumentos centrais acerca do status da cultura enquanto esfera relativamente autônoma da vida social, capaz de influenciar atitudes e comportamentos através da composição de uma estrutura imaterial formada por padrões simbólicos ampliados que originam códigos culturais capazes de dar sentido aos mais diversos tipos de processos sociais.

Foi com base nesse amplo programa de pesquisa que Alexander então estabeleceu o seu conceito de esfera civil, como chave analítica privilegiada para a interpretação dos processos sociais e políticos do mundo contemporâneo sob uma perspectiva cultural. Segundo o autor, em contraste com o conceito historicamente mais antigo e analiticamente menos preciso de

\footnotetext{
${ }^{\star}$ Doutor em Sociologia pela Boston University, Professor Associado do Departamento de Ciências Sociais e do Programa de Pós-Graduação em Sociologia da Universidade Federal da Paraíba - UFPB. Fulbright Visiting Scholar no Afro-Latin American Research Institute, da Harvard University no período 2018-2019. E-mail: medeirosrogerio@ hotmail.com.
} 
"sociedade civil", a esfera civil deve ser compreendida como uma arena analiticamente distinta e empiricamente diferenciada do Estado e do mercado, enquanto uma esfera de solidariedade onde se constitui culturalmente e se consolida institucionalmente uma espécie de comunidade democrática universalizante que se baseia e se sustenta em profundos códigos culturais, na opinião pública, em instituições específicas e em práticas interativas historicamente definidas. Enquanto tal, a esfera civil é orientada por códigos culturais democráticos de larga abrangência e fortemente marcada pelo discurso da liberdade e da solidariedade, sem se reduzir a uma mera linguagem social.

A cultura da esfera civil se institucionaliza através de instituições que conectam os seus valores culturais mais amplos a eventos especificamente definidos no tempo e no espaço, através da construção e do uso de categorias interpretativas. Enquanto uma esfera de solidariedade, uma comunidade civil deste tipo não pode existir enquanto tal, ela apenas pode ser sustentada, em contraste e em tensão com esferas e tendências não civis, no estabelecimento de relações limítrofes (boundary relations).

O estudo da esfera civil, portanto, aponta sempre para uma tensão constitutiva da vida política moderna, entre o ideal e o real, entre ideais utópicos de alargamento da solidariedade e aprofundamento da democracia e a continuidade ou o agravamento de desigualdades e injustiças materiais e políticas. A análise dos movimentos sociais pela Teoria da Esfera Civil (TEC) ilustra bem esse ponto. Os movimentos sociais emergem exatamente das tensões entre esferas civis ideais e reais. Essas formas de ação coletiva operam uma espécie de tradução, enquadrando situações e problemas específicos, derivados de relações sociais particularistas, segundo a linguagem universalizante de uma esfera civil ideal, de valores morais democráticos. Com isso, os movimentos sociais apelam para uma esfera civil normativa, na busca pela realização de reparos civis, e procuram deslocar questões e disputas das esferas não civis de onde elas se originam e trazê-las para uma posição em que possam ser tratadas segundo parâmetros mais democráticos e solidários e, com isso, deixem de ser uma questão de interesse de apenas uma parte da sociedade para tornar-se uma questão de interesse de toda a sociedade. É precisamente essa a chave analítica utilizada pelo autor, no livro de 2006 para interpretar tanto o movimento feminista, quanto o movimento pelos Direitos Civis nos Estados Unidos (MEDEIROS, 2008).

Organizado por Alexander e Carlo Tognato, The Civil Sphere in Latin America (2018) consiste em uma coletânea de estudos sobre processos políticos localizados em países da América Latina em que fenômenos aparentemente tão diversos quanto o movimento de mulheres argentinas contra o feminicídio, escândalos de corrupção no Chile ou um caso de ciberativismo em Cuba são analisados à luz da Teoria da Esfera Civil.

Há basicamente dois registros segundo os quais o livro pode ser interpretado enquanto contribuição para o debate acadêmico sobre processos políticos relevantes no mundo contemporâneo. Aliás, os dois estão mais ou menos implicitamente sugeridos na introdução do livro escrita pelos organizadores. Esses registros não são necessariamente excludentes ou 
mesmo contraditórios. Podem significar simplesmente dois níveis de leitura para o conjunto de estudos que o livro apresenta. Por um lado, a coletânea pode ser lida como a primeira tentativa de reunir em um só volume pesquisas que, em conjunto, procuram testar o fôlego da Teoria da Esfera Civil, formulada há doze anos, para dar conta de uma variedade muito grande de problemas, temáticas e contextos. Aliás, esse parece mesmo ser um dos objetivos do projeto editorial em que o livro se insere, conforme indica o prefácio da obra, que prevê o lançamento de pelo menos dois outros volumes, um sobre o Leste da Ásia e o outro sobre a esfera civil nos países nórdicos. Segundo essa linha de leitura, o livro seria basicamente uma espécie de exercício analítico pela aplicação prática do aparato conceitual fornecido pela Teoria da Esfera Civil. Nessa linha, podemos perceber no capítulo escrito por María Angélica Thumala Olave, sobre escândalos de formação de cartel entre empresas no Chile, a aplicação dos conceitos e ideias da Teoria da Esfera Civil para interpretar as junções e disjunções entre códigos culturais distintos, dos processos de justificação do capitalismo chileno, de um lado, e das experiências cotidianas de desigualdade e injustiça, de outro, apresentando uma aplicação direta da TEC para compreender o encadeamento de processos a partir da comoção pública gerada pelos escândalos, transformada em indignação, enquanto catalisadora para tentativas de realização de reparos civis, por vias institucionais (legais) e não institucionais (protestos e boicotes) através da mobilização da opinião pública. O mesmo tipo de aplicação é encontrado no capítulo sobre a atuação da Política Militar do Estado de São Paulo, em que Mayumi Shimizu analisa as contradições entre os aspectos civis da polícia enquanto instituição reguladora da esfera civil e os meios não civis pelos quais operam seus agentes.

Um outro registro para a leitura da obra seria considerá-la como algo mais do que uma simples aplicação da TEC para atestar a sua relevância explicativa. Seria o caso de buscar na coletânea novas perspectivas e interpretações para problemas recentes enfrentados pelas democracias latino-americanas, em consonância com o programa de pesquisa mais amplo e mais antigo desenhado por Alexander para o campo de uma Sociologia Cultural. Seria o caso de, por um lado, tentar enxergar a relevância e a centralidade de processos culturais abrangentes para compreender problemas como a ascensão de discursos e lideranças antidemocráticas, o declínio da importância dos "fatos" como lastro para o debate político contemporâneo, processos de extrema polarização política e de demonização de partidos de oposição, e por outro lado, verificar como essas experiências latino-americanas interpelam e questionam "a condescendência com que estudiosos do Norte frequentemente têm abordado a vida democrática fora dos Estados Unidos e da Europa." (p.11). Nesse sentido, o livro também traz as experiências dos países latino-americanos como desafios para a própria Teoria da Esfera Civil, revelando muito das suas limitações e inadequações. Entre outras coisas, essas experiências revelam a necessidade de lidar não apenas com as potencialidades da esfera civil em promover reparos civis para situações de injustiças materiais ou simbólicas, mas também, e talvez ainda mais importante, a urgência de se compreender mais profundamente as dinâmicas envolvidas nas disputas entre forças e processos 
civis, não civis e anticivis. Essas tensões são mais claramente explicitadas nos capítulos escritos por Celso M. Villegas (sobre os usos civis e não civis do sentido de "classe média" na Venezuela), por Carlo Tognato (sobre as tensões entre os discursos civil, revolucionário e patrimonial em uma controvérsia pública envolvendo a Universidade Nacional em Bogotá) e no capítulo escrito por Nelson Arteaga Botello e Javier Arzuaga Magnoni (sobre as tensões entre democracia e autoritarismo no processo histórico de configuração da esfera civil no México).

Seja por um ou outro registro, o livro fornece contribuições relevantes para o debate acerca dos desafios enfrentados pelas democracias latino-americanas de hoje. Lança luz diretamente sobre as potencialidades e as limitações de uma abordagem assumidamente cultural, que tem pretensões de rivalizar com tradições explicativas mais fortemente enraizadas na academia latino-americana, a exemplo da tradição marxista ou, mais recentemente, dos estudos póscoloniais.

Qualquer que seja o êxito alcançado por essa empreitada intelectual, a forma como a obra considera os casos latino-americanos constitui em si uma novidade, rejeitando velhas formulações que tomavam as democracias da região como incompletas, atrasadas ou antimodernas. De fato, em conjunto, os estudos que compõem o livro procuram demonstrar que a esfera civil na América Latina, apesar de constantemente fragmentada e muitas vezes comprometida por problemas estruturais profundos, mantém culturalmente e institucionalmente a sua força e a sua resistência, sendo capaz de dar origem a movimentos contestatórios politicamente relevantes, empreendimentos intelectuais críticos e inovadores, partidos políticos críticos e com renovado poder eleitoral. Nesse sentido, a instabilidade e a fragilidade da esfera civil na América Latina não é maior do que em qualquer outra parte, mas o conhecimento sobre as particularidades dos desafios enfrentados na região pode e deve contribuir para iluminar alguns dos principais problemas encontrados em qualquer sociedade democrática contemporânea, principalmente no que diz respeito aos embates entre atores políticos e processo sociais civis, não civis e anticivis.

\section{Referências}

ALEXANDER, J. C.; SMITH, P. The discourse of American civil society: a new proposal for cultural studies. Theory and Society, v. 22, n. 2, p. 151-207, Apr. 1993.

The Civil Sphere. New York: Oxford University Press, 2006.

The Civil Sphere. New York: Oxford University Press, 2006. Resenha de: MEDEIROS, R. S. Estudos de Sociologia: Revista do Programa de Pós-Graduação em Sociologia da UFPE, Recife, v.14, n.1. p.203-210, 2008.

; TOGNATO, Carlo. (Orgs.). The Civil Sphere in Latin America. Cambridge, UK: Cambridge University Press, 2018.

Recebido em: 04/02/2019

Aceito em: 04/02/2019 